\title{
O DECRETO No 2.208/1997 E A LEI No 13.415/2017: UMA REFLEXÃO PARA ALÉM DAS "COINCIDÊNCIAS"
}

\section{DECREE NO. 2.208/1997 AND THE LAW NO. 13.415/2017: A REFLECTION BEYOND "COINCIDENCES"}

\author{
SOUZA, Francisco Chagas Silva ${ }^{1}$ \\ JÚNIOR, José Gerardo Bastos da Costa² \\ SOUZA, Francisca Leidiane de ${ }^{3}$ \\ LIMA, Ana Paula Marinho de ${ }^{4}$
}

\section{RESUMO}

As políticas para a educação brasileira têm sido marcadas pela dualidade. Em geral, estabelecem duas propostas de formação: uma, para a elite econômica e política; e outra, destinada aos trabalhadores e aos interesses do mercado. Neste artigo, discutimos o Decreto no $2.208 / 1997$ e a Lei $n^{\circ} 13.415 / 2017$, comparando-os, visto que ambos estabeleceram reformas importantes na educação brasileira. A metodologia constou de uma revisão bibliográfica a partir de estudos elaborados por pesquisadores do campo Trabalho e Educação, quanto às suas análises acerca desses dois documentos. Constatamos que, apesar do espaço temporal de vinte anos entre os dois dispositivos legais, há muitas "coincidências" que só podem ser compreendidas a partir da adoção do ideário neoliberal pelos governos Fernando Henrique Cardoso e Michel Temer.

Palavras-Chave: Educação Profissional; Dualidade; Ensino Médio; Política educacional; Neoliberalismo.

\section{ABSTRACT}

Policies for Brazilian education have been marked by duality. In general, they establish two formation proposals: one, for the economic and political elite; and another, aimed at workers

\footnotetext{
${ }^{1}$ Doutor em educação (UFRN) e professor do Programa de Pós-graduação em Educação Profissional (IFRN), do Programa de Pós-graduação em Educação Profissional e Tecnológica (PROFEPT) e do Programa de Pós-graduação em Ensino (UERN/IFRN/UFERSA). Rio Grande do Norte, RN, Brasil. email: chagasifrn@gmail.com

${ }^{2}$ Licenciado em História (UECE) e Mestre em Ensino (UERN/IFRN/UFERSA), professor do Instituto Federal de Educação, Ciência e Tecnologia do Rio Grande do Norte, Campus Mossoró. Rio Grande do Norte, RN, Brasil. e-mail: gerardo.junior@ifrn.edu.br

${ }^{3}$ Bacharela em Turismo (UERN) e Mestre em Ensino (UERN/IFRN/UFERSA). Rio Grande do Norte, RN, Brasil. e-mail: leidy_uerntour@hotmail.com

${ }^{4}$ Licenciada em Pedagogia (UERN) e mestranda em Ensino (UERN/IFRN/UFERSA). Rio Gende do Norte, RN, Brasil. e-mail: ninapaula01@hotmail.com
} 
DOI: $10.12957 / \mathrm{e}-\mathrm{mosaicos} .2019 .46589$

and market interests. In this article, we discuss the Decree No. 2.208/1997 and Law No. 13.415/2017 comparing them as both established important reforms in Brazilian education. The methodology consisted of a literature review based on studies prepared by researchers in the field of Work and Education, regarding their analysis of these two documents. We see that, despite the twenty-year time span between the two legal provisions, there are many "coincidences" that can only be understood from the adoption of neoliberal ideas by Fernando Henrique Cardoso and Michel Temer governments.

KeYWORDS: Professional education; Duality; High school; Educational politics; Neoliberalism.

\section{INTRODUÇÃo}

Entre os pesquisadores marxistas, é ponto pacífico a compreensão do trabalho como princípio educativo e elemento constituidor da Humanidade, e que essa relação se rompe com a divisão da sociedade em classes (SAVIANI, 1989, 2003, 2007). Diante disso, consideramos importante iniciar este artigo salientando a dualidade que marca a história da educação brasileira e que, para Kuenzer (2009), torna-se estrutural a partir da década de 1940, com as Leis Orgânicas do Ensino, conhecidas como Reforma Capanema, nos últimos anos do governo do presidente Getúlio Vargas.

No Brasil, essa dualidade assume maior evidência no Ensino Médio, gerando uma disputa entre dois projetos de currículo: de um lado, uma proposta de formação geral, preocupada com a construção de um sujeito que saiba articular trabalho, ciência, tecnologia e cultura; e, de outro, uma propositura de formação profissionalizante, cuja meta é educar o trabalhador cidadão produtivo e não o ser humano emancipado (FRIGOTTO; CIAVATTA, 2003). Obviamente, essa separação não é natural, mas consequência de uma sociedade cindida em classes, na qual os interesses não são apenas distintos, mas conflitantes.

No século $X X$, em alguns cenários históricos brasileiros, essa dualidade foi acentuada e, em outros, flexibilizada, mas nunca extinta. Exemplos disso são os Decretos no 2.208, de 17 de abril de 1997 (BRASIL, 1997a) e o no 5.154, de 23 de julho de 2004 (BRASIL, 2004), respectivamente nos governos dos presidentes Fernando Henrique Cardoso (FHC) e Luiz Inácio Lula da Silva. O primeiro Decreto legitima e evidencia um projeto de separação e oposição entre a formação geral e a profissional, enquanto o segundo procurou unir essas esferas por meio da criação da forma Integrada no Ensino Médio. Para Ciavatta (2012, p. 84), espera-se que, com essa formação integrada, "[...] a educação geral se torne parte inseparável da educação profissional em todos os campos onde se dá a preparação para o trabalho: seja nos processos produtivos, seja nos processos educativos [...]". Apesar dos avanços trazidos pelo Decreto do presidente Lula, este manteve as formas 
DOI: $10.12957 / \mathrm{e}-\mathrm{mosaicos} .2019 .46589$

Subsequente e Concomitante, criadas pelo Decreto de FHC, gerando críticas ao governo.

Todavia, se avançamos alguns passos, retrocedemos outros. No governo do presidente Michel Temer, que ascendeu à presidência quando do impeachment da presidenta Dilma Roussef, foi aprovada a Lei no 13.415, em 16 de fevereiro de 2017, que, mais uma vez, reforma o Ensino Médio, oficializa a dualidade e põe em risco a manutenção da forma integrada nos cursos técnicos de nível médio (BRASIL, 2017a).

Neste artigo, objetivamos apresentar o Decreto no 2.208/1997 e a Lei no 13.415/2017 considerando os contextos histórico e socioeconômico em que foram criados e as semelhanças (que não consideramos meras coincidências) entre esses dois dispositivos legais, embora estejam separados por duas décadas. Para isso, pautamo-nos em uma pesquisa bibliográfica a partir das publicações de pesquisadores do campo Trabalho e Educação, sobretudo daqueles que se filiam ao Grupo de Trabalho 09 da Associação Nacional de Pós-Graduação e Pesquisa em Educação (ANPED).

\section{O DECRETO No 2.208/1997 E A LEI No 13.415/2017: A DUALIDADE ESCANCARADA}

Ao apresentar uma obra publicada por Araújo (2019), Frigotto comenta que "[...] ao longo de nossa história, a universalização do ensino médio e a educação profissional integrada à educação básica de nível médio foram e são sistematicamente negados ou truncados por contrarreformas [...]" (2019, p. 3). Em poucas linhas, Frigotto resume um aspecto das políticas educacionais voltadas ao Ensino Médio no Brasil: a cisão entre uma proposta de educação que forma o sujeito em sua amplitude; e um ensino voltado para as demandas do mercado de trabalho, logo, despreocupado com a formação para além dos manuseios de equipamentos que fazem reproduzir o capital.

Assim, os discursos da empregabilidade, da qualidade total, das competências, estudados por Frigotto (2018), Oliveira (2009), Araújo e Rodrigues (2010), dentre outros pesquisadores do campo Trabalho e Educação, servem de esteio para ações governamentais, que, rezando na cartilha do neoliberalismo, caminham no sentido de materializar a proposta de uma "escola interessada", semelhante ao que foi advertido por Gramsci há quase um século:

Na escola atual, em função da crise profunda da tradição cultural e da concepção da vida e do homem, verifica-se um processo de progressiva degenerescência: as escolas de tipo profissional, isto é, preocupadas em satisfazer interesses práticos imediatos, predominam sobre a escola formativa, imediatamente desinteressada. O aspecto paradoxal reside em que este novo tipo de escola aparece e é louvado como democrático, quando na realidade, não só é destinado a perpetuar as diferenças sociais, como ainda a cristalizá-las em 
No Brasil, apesar do discurso neoliberal ter sido uma característica das gestões dos presidentes Fernando Collor de Mello (1990-1992) e Itamar Franco (1992-1995), foi nos dois mandatos do presidente Fernando Henrique Cardoso (1995-2003) que esse ideário teve um aprofundamento, haja vista que, ao assumir a presidência, em 1995, FHC já havia se articulado com os organismos internacionais para a elaboração de projetos que pautassem a privatização de estatais e a descentralização do Estado ${ }^{5}$. Ou seja, dava-se prosseguimento à "desestatização" tão alardeada no governo Collor e prosseguida no governo Itamar Franco.

Foi no governo FHC que se deu a criação do Decreto no 2.208/1997, cujo traço característico foi a separação entre a formação geral e a profissional expressa no seu Artigo 50: "A educação profissional de nível técnico terá organização curricular própria e independente do ensino médio, podendo ser oferecida de forma concomitante ou seqüencial a este" (BRASIL, 1997a) $)^{6}$. No mês seguinte, o governo publicou a Portaria $n^{\circ} 646$, com os objetivos de regulamentar os artigos 39 a 42 da Lei de Diretrizes e Bases da Educação Nacional (LDB) e implantar o referido Decreto no prazo de quatro anos. 0 artigo $3^{\circ}$ dessa Portaria orientava que a oferta do Ensino Médio poderia ser mantido, mas "com matrícula independente da educação profissional, oferecendo o máximo de $50 \%$ do total de vagas oferecidas para os cursos regulares em 1997" (BRASIL, 1997b) ${ }^{7}$.

Para fazer frente a tal proposta, cinco meses depois do Decreto $n^{\circ}$ 2.208/1997, foi lançada a Portaria no 1.005/1997, cuja intensão era implementar o Programa de Reforma da Educação Profissional - PROEP (BRASIL, 1997c). Esse Programa dispunha de 500 milhões de dólares, sendo 250 milhões obtidos por empréstimos do Banco Internacional de Desenvolvimento (BID), 125 milhões do Fundo de Amparo ao Trabalhador (FAT) e 125 milhões do orçamento do Ministério da Educação (BRASIL, 2006).

Em síntese, com a Reforma da Educação Profissional, imposta por FHC, os cursos técnicos de nível médio passaram a ter um currículo próprio, devidamente separado do Ensino Médio, e deveriam se desenvolver com base no conceito de competência, vislumbrando um perfil de trabalhador capaz de se adequar às constantes mudanças do mercado. Por isso, as Diretrizes Curriculares Nacionais para a Educação Profissional de Nível Técnico, instituídas pela Resolução CNE/CEB no 04/1999, no seu artigo $6^{\circ}$ entendem como competência profissional a "[...] capacidade de articular, mobilizar e colocar em ação valores, conhecimentos e habilidades necessários para o desempenho eficiente e eficaz de atividades

\footnotetext{
${ }^{5} \mathrm{Em} 19$ de maio de 1993, FHC foi nomeado Ministro da Fazenda pelo Presidente Itamar Franco. Até então era Ministro das Relações Exteriores. Ou seja, FHC teve o tempo necessário para fazer vários acordos com as agências multilaterais.

${ }^{6}$ Grifo nosso.

${ }^{7}$ Grifo nosso.
} 
DOI: $10.12957 / \mathrm{e}-\mathrm{mosaicos} .2019 .46589$

requeridas pela natureza do trabalho" (BRASIL, 1999, p. 4).

Portanto, tratava-se de uma concepção de ensino que não possibilitava ao educando uma compreensão do mundo e de sociedade de maneira reflexiva e crítica, mas uma aprendizagem de conhecimentos técnicos de forma mecânica e pragmática, muito próxima à educação bancária de que fala Paulo Freire na "Pedagogia do Oprimido" (2012). Em face disso, para Kuenzer (1997, p. 95) a proposta da Reforma é "tão anacrônica e confusa que não serve sequer ao capital, que tem mais clareza do que o próprio MEC sobre as demandas de formação de um trabalhador de novo tipo, numa perspectiva menos retrógrada de superação do Taylorismo".

Portanto, reiteramos que a implantação do Decreto no 2.208/1997 não pode ser compreendida fora do contexto histórico dos fins do século XX, quando o Brasil adota uma série de ajustes cujos alicerces eram as premissas neoliberais. Nesse cenário, palavras como meritocracia, flexibilização, competitividade, desregulamentação, requalificação, qualidade total, competência e Estado Mínimo nortearam um conjunto de reformas socioeconômicas e educacionais, amparadas pelo discurso da modernização e do desenvolvimento, vinculados aos ditames do mercado nacional e internacional.

Para executar as reformas, o governo FHC criou o Ministério da Administração e Reforma do Estado (MARE), tendo à frente o economista Luís Carlos Bresser Pereira. A partir de então, foi definida uma agenda pública, com base nos interesses do mercado e com ênfase na privatização, na liberação comercial ${ }^{8}$ e na abertura externa.

Aos poucos, o neoliberalismo, ou a "nova ordem mundial", conquistou espaços utilizando-se da mídia para convencer a sociedade, apresentando-se como única alternativa a ser seguida pelos países em crise e preconizando a ideologia do "Estado Mínimo". Alardeava-se que a privatização traria o desenvolvimento ao reduzir as despesas do Estado.

Contudo, conforme Oliveira (2003), a reforma pautada no modelo neoliberal representou um retrocesso no que concerne ao desenvolvimento social, uma vez que a reestruturação do estado brasileiro baseou-se no retrocesso da ação estatal no campo social, arquitetado sobre um molde segregador e excludente.

A educação, ajustada e condicionada às influências internacionais, tornou-se ferramenta indispensável para o êxito do processo de modernização (o Decreto no 2.208/1997 é um exemplo disso). Nesse contexto, as políticas educacionais

\footnotetext{
${ }^{8}$ O Programa de Liberação Comercial fez parte do Decreto $n^{\circ}$ 350/1991 e consistiu em reduções tarifárias progressivas, lineares e automáticas, acompanhadas da eliminação de restrições não tarifárias ou medidas de efeito equivalente, assim como de outras restrições ao comércio entre os Estados Partes, para chegar a 31 de dezembro de 1994 com tarifa zero, sem barreiras não tarifárias sobre a totalidade do universo tarifário. A partir dessa data, os Estados Partes passaram a constituir o "Mercado Comum do Sul" - MERCOSUL (BRASIL, 1991).
} 
DOI: $10.12957 / \mathrm{e}-\mathrm{mosaicos} .2019 .46589$

ganharam importância ao se apoiarem na literatura internacional, recuperando ideias da Teoria do Capital Humano, desenvolvida por Theodore Schultz nos anos 1960. Segundo Shiroma, Moraes e Evangelista (2011, p. 47), tal teoria afirmava "[...] ser a educação um dos principais determinantes da competitividade entre os países. Alegava-se que o novo paradigma produtivo demandava requisitos diferenciados de educação geral e qualificação profissional dos trabalhadores". Para as autoras, de forma mecânica e repentina, é atribuído à educação "o condão" que sustentaria a competitividade nos anos de 1990.

Nessa direção, Oliveira (2003) considera que a educação passou a servir de "válvula de escape" para a afirmação do modelo implementado ao alimentar uma antiga máxima salvacionista que se materializou por meio da intervenção dos organismos multilaterais. O autor em tela conclui que o governo brasileiro não arcou com a atribuição de reduzir os efeitos negativos da globalização e consolidou um discurso que transferia aos indivíduos a incumbência de competir por uma melhor colocação no mercado de trabalho.

Logo, foi atribuída à educação, em especial, à Educação Profissional, aspectos econômicos, baseados em indicadores financeiros, considerando unicamente seu custo-benefício. Para Frigotto (2006), as políticas de educação escolar e de formação técnico-profissional que se concretizaram na hegemonia neoliberal procuraram, não sem incoerências, o cultivo das qualificações necessárias ao funcionamento da economia nos setores limitados que exigiam trabalho complexo, a expansão da formação para o trabalho simples e a concepção de quadro para a elaboração e a dispersão da pedagogia da hegemonia.

A eleição do presidente Luís Inácio Lula da Silva, em 2003, trouxe um rompimento com a proposta de educação do governo $\mathrm{FHC}$, a partir do Decreto no 5.154/2004. Mesmo que tenha mantido as formas Subsequente e Concomitante, presentes no Decreto no 2.208/1997, o Decreto do presidente Lula inseriu a Integração como uma das formas de articulação entre a formação geral, propedêutica, e a formação técnica, profissional (BRASIL, 2004).

Assim, o Ensino Médio Integrado (EMI) passou a ser a bandeira de luta dos educadores progressistas ao ser concebido como uma possibilidade de superação da dualidade na educação brasileira, conforme defendem Frigotto, Ciavatta e Ramos (2012); Moura (2007); Moura, Lima Filho e Silva (2015). Esses pesquisadores compreendem que as intenções e as possibilidades do Decreto no 5.154/2004 eram permitir, aos jovens da classe trabalhadora, uma formação que pudesse unir e contemplar a ciência, a tecnologia, o trabalho e a educação de forma indissociável. Portanto, há aí a esperança da construção de uma escola politécnica, não assentada, obviamente, no ensino de várias técnicas, mas na articulação entre o trabalho manual e o intelectual, possibilitando ao estudante ser capaz de compreender e aplicar o conhecimento que adquiriu (SAVIANI, 2003).

Em função disso, são muitas as publicações acerca do EMI, como observam Souza, Souza e Costa Júnior (2018), mas, por outro lado, é inexpressiva a produção 
DOI: $10.12957 / \mathrm{e}-\mathrm{mosaicos} .2019 .46589$

acadêmica acerca da Concomitância, como destaca o levantamento feito por Lima, Souza e Souza (2018) no Catálogo de Teses e Dissertações da Coordenação de Aperfeiçoamento de Pessoal de Nível Superior (Capes). Para estes últimos, a oferta de cursos concomitantes é pouco estudada ou, mesmo invisibilizada, pelos estudiosos do campo da Educação Profissional, por uma perspectiva política de "[...] dar realce ao Ensino Médio Integrado, visto, pela maioria destes, como uma possível travessia para uma educação politécnica e voltada para a formação do sujeito em sua plenitude" (LIMA; SOUZA; SOUZA, 2018, p. 59).

A proposta e a prática da Integração entre o Ensino Médio e a Educação Profissional vêm sendo mantida desde as gestões do presidente Lula (2003-2011). Entretanto, a partir do governo do presidente Michel Temer (2016-2018), que chegou ao poder com o impeachment da presidenta Dilma Roussef (2011-2016), o cenário tornou-se de total insegurança quanto à manutenção dessa forma de oferta na Educação Profissional. Propostas esdrúxulas como a "Escola Sem Partido" e a perseguição a docentes e discentes questionadores, adjetivados de "esquerdistas", e geradores de "balbúrdias" nas escolas têm se configurado numa verdadeira caça às bruxas.

Alegando uma redução quantitativa e qualitativa do Ensino Médio, revelada pela diminuição de matrículas, dos baixos índices de aproveitamento escolar dos educandos e dos altos números de evasão, o ex-presidente Temer propôs a Medida Provisória no 746, em 22 de setembro de 2016, poucos meses depois transformada na Lei no 13.415, em 16 de fevereiro de 2017, tendo esta a finalidade de reformar 0 Ensino Médio (MOLL, 2017).

Uma análise crítica da Lei no 13.415/2017, considerando o cenário histórico e político em que foi criada, leva-nos a estabelecer uma relação desta com o projeto neoliberal, presente no Brasil desde as últimas décadas do século XX. Assim como o Decreto no 2.208/1997, essa Lei não só fortalece a dualidade no Ensino Médio, mas também vai ao encontro do ideário neoliberal, como observam Moura e Lima Filho (2017, p. 111). Para eles, a Lei:

[...] está abrigada por uma racionalidade maior, que alberga um conjunto de medidas, em curso ou em elaboração, cujo objetivo é reconfigurar o Estado brasileiro no sentido de torná-lo ainda "mais mínimo" no que se refere às garantias dos direitos sociais e "mais máximo" para regular os interesses do grande capital nacional e internacional, especialmente o financeiro/especulativo. Trata-se, assim, de uma nova fase de radicalização do neoliberalismo, que visa

\footnotetext{
${ }^{9}$ O Programa Escola Sem Partido é um movimento político que atua desde 2004 no Brasil, divulgado pelo advogado Miguel Nagib, que se diz contra a doutrinação ideológica político-partidária nas escolas. Setores políticos conservadores tentaram transformar esse Programa em um projeto de lei, chegando a aprovar em alguns municípios, mas foi considerado inconstitucional pelo Supremo Tribunal Federal (STF).
} 
perpetrar um golpe contra a classe trabalhadora mais pobre do País, alcançada pelas políticas públicas inclusivas das duas primeiras décadas deste século.

O chamado "Novo Ensino Médio" é composto por dois blocos articulados e indissociáveis: a Formação Geral Básica, referenciada na Base Nacional Comum Curricular (BNCC); e nos Itinerários Formativos, a partir dos quais os alunos poderão "escolher" o que desejam aprender, conforme os seus interesses e as possibilidades de ofertas das redes e escolas. Por conseguinte, assemelha-se ao Decreto $n^{0}$ 2.208/1997, pela separação entre os tipos de formação, impossibilitando assim, uma formação omnilateral do sujeito.

Segundo os Referenciais Curriculares para a Elaboração de Itinerários Formativos (BRASIL, 2017b, p. 4), estes deverão atender a quatro objetivos:

a) Aprofundar e ampliar as aprendizagens relacionadas às competências gerais, às áreas de conhecimento e/ou à Formação Técnica e Profissional;

b) Consolidar a formação integral dos estudantes, desenvolvendo a autonomia necessária para que realizem seus projetos e vida;

c) Promover a incorporação de valores universais, como ética, liberdade, democracia, justiça social, pluralidade solidariedade e sustentabilidade;

d) Desenvolver habilidades que permitam aos estudantes ter uma visão de mundo ampla e heterogênea, tomar decisões e agir nas mais diversas situações, seja na escola, seja no trabalho, seja na vida.

Seguindo ainda a lógica desse documento acima mencionado, os itinerários formativos propõem que o educando possa "mergulhar" em uma ou mais das determinadas áreas de conhecimento, a saber: Linguagens e suas Tecnologias; Matemática e suas Tecnologias; Ciências da Natureza e suas Tecnologias; Ciências Humanas e Sociais aplicadas e Formação Técnica e Profissional. Este quinto itinerário terá o papel de promover a qualificação dos estudantes para o mercado do trabalho, sendo, de acordo com Araújo (2019, p. 61), o "itinerário dos pobres".

Uma análise do que está exposto Referenciais Curriculares para a Elaboração de Itinerários Formativos, quanto ao Itinerário da Formação Técnica e Profissional, leva-nos a pensar a Educação Profissional, conforme concebe Manfredi (2016). Essa autora, ao discutir sobre as diferenças entre os termos "trabalho" e "emprego" defende que a Educação Profissional "[...] como prática social, é uma realidade condicionada, determinada e não condicionante de qualificação social para o trabalho 
DOI: $10.12957 / \mathrm{e}-\mathrm{mosaicos} .2019 .46589$

e para o emprego" (2016, p. 35).

Ainda referente aos Itinerários Formativos, estes estão organizados a partir de quatro eixos estruturantes. O primeiro trata da Investigação Científica, o qual propõe ampliar a capacidade científica do aluno para investigar a realidade por meio da realização de produções científicas. O segundo, Processos Criativos, tem como finalidade expandir a capacidade dos sujeitos para a idealização e realização de projetos que tenham como foco a criatividade. O terceiro, Mediação e Intervenção Sociocultural, busca capacitar o aluno para o desenvolvimento de projetos que tenham relação direta com o meio social em que está inserido, além do meio ambiente. O quarto, Empreendedorismo, tem como objetivo central expandir a capacidade do educando no sentido de mobilizar conhecimentos nas diferentes áreas para empreender os seus projetos pessoais articulados ao seu projeto de vida. Dito isto, o educando, segundo o Documento de orientação, deverá optar por pelo menos um desses eixos estruturantes (BRASIL, 2017b).

Se tratarmos especificamente do quarto eixo estruturante, podemos conjecturar que a intenção do novo projeto para o Ensino Médio, dentre outros interesses, é a de responsabilizar o próprio educando pela sua ascensão profissional. Assim, aquele que não desenvolver a sua capacidade para empreender não terá como justificar tal "falta" de conhecimento/preparação na sua formação básica, já que o novo currículo foi pensado para atender aos diferentes saberes. Dessa maneira, como explica Harvey (2008, p. 76): "Embora a liberdade pessoal e individual no mercado seja garantida, cada indivíduo é julgado responsável por suas próprias ações e por seu próprio bem-estar, do mesmo modo como deve responder por eles".

Importa destacar que palavras como "qualificação", "liberdade", "autonomia", "mercado de trabalho", "empregabilidade", dentre outras, aparecem exaustivamente nos documentos oficiais e nas campanhas publicitárias do MEC transmitidas, sobretudo, nos canais abertos de televisão. Isso demonstra a necessidade que o neoliberalismo tem de fortalecer conceitos que lhe servem de base e de argumento, como observa Harvey (2008, p. 15):

Nenhum modo de pensamento se toma dominante sem propor um aparato conceitual que mobilize nossas sensações e nossos instintos, nossos valores e nossos desejos, assim como as possibilidades inerentes ao mundo social que habitamos. Se bem-sucedido, esse aparato conceituai se incorpora a tal ponto ao senso comum que passa a ser tido por certo e livre de questionamento. As figuras fundadoras do pensamento neoliberal consideravam fundamentais os ideais políticos da dignidade humana e da liberdade individual, tomando-os como "os valores centrais da civilização". Assim agindo, fizeram uma sábia escolha, porque esses certamente 
Segundo o autor em tela, na história do neoliberalismo, os detentores do poder sustentavam que valores como liberdade e dignidade humana "[...] estavam ameaçados não somente pelo fascismo, pelas ditaduras e pelo comunismo, mas também por todas as formas de intervenção do Estado que substituíssem os julgamentos de indivíduos dotados de livre escolha por juízos coletivos". Ou seja: não é mera coincidência que hoje, em fins da segunda década do século XXI, haja uma disseminação do pavor da "volta" do comunismo.

Nesse aspecto, consideramos importante a ponderação feita por Silva (1996) a respeito do termo "reforma". Para o autor, essa palavra

[...] designava transformações sociais dirigidas à diminuição de privilégios, hierarquias e desigualdades, passa a designar, quase que exatamente o seu oposto, ou seja, mudanças nas instituições e nas estruturas orientadas ao reforço de posições de privilégio e desigualdade, de tal forma que somos colocados na posição "indesejável" de sermos contra as "reformas"! (SILVA, 1996, p. 169169).

Com relação ao itinerário que isola a formação profissional das outras, Krawczyk e Ferretti (2017, p. 39) assim se posicionam:

Ignorar a formação geral no nível técnico é a princípio incongruente com a visão do mundo do trabalho nos moldes do capitalismo atual, a não ser que se queira treinar os jovens para serem simplesmente operários no chão da fábrica ou trabalhadores sem chances no mercado formal, travestidos de "empreendedores".

Permitir que o jovem escolha aquilo que deseja aprender e conhecer, é uma forma "mascarada" ou um meio encontrado pela direita neoliberal para incluir o educando (dando a este o poder de escolha), com o discurso de "engajamento e protagonismo", para, em seguida, excluí-lo das decisões sociais. Estamos diante de uma "inclusão excludente", conforme discute Kuenzer (2005), ou mesmo uma "reforma para retardar", como afirma Moll (2017).

Compreendemos que o "Novo Ensino Médio" e outras "novidades" como os programas "Future-se" e "Novos Caminhos", implantados pelo atual presidente Jair Messias Bolsonaro, porta-voz da direita brasileira e estadunidense, chocam-se com a

${ }^{10}$ Grifos nossos. 
DOI: $10.12957 / \mathrm{e}-m o s a i c o s .2019 .46589$

proposta do Ensino Médio Integrado, trazida pelo Decreto no 5.154/2004, haja vista que objetiva uma formação completa e integrada, buscando "[...] superar o histórico conflito existente em torno do papel da escola, de formar para a cidadania ou para o trabalho produtivo [...]" (RAMOS, 2012, p. 121).

Além disso, assim como o Decreto no 2.208/1997, que divorciou a formação geral da profissional e teve como meta a formação rápida para atender à lógica do mercado, a Reforma que implantou o Novo Ensino Médio e os itinerários formativos, em substituição à ideia de formação básica comum, oferta aos jovens de origem trabalhadora "[...] uma 'educação escolar mínima', rasteira, instrumental aos ofícios a eles 'predestinados' e para os quais são necessários apenas os chamados 'saberes de base"' (ARAÚJO, 2019, p. 69).

\section{CONSIDERAÇões Finais}

O Decreto no 2.208/1997 e a Lei no 13.415/2017 trouxeram reformas profundas no Ensino Médio, sobretudo no que diz respeito à Educação Profissional. Pelas semelhanças entre esses dispositivos legais, resolvemos analisá-los considerando o cenário em que foram produzidos e implantados.

Inferimos que há uma série de "coincidências" entre o Decreto e a Lei, pois ambos se identificam com a filosofia produtivista, tendo como base 0 aprofundamento das propostas neoliberais. Os documentos estão em consonância com as exigências dos organismos multilaterais, que reivindica uma reorganização do trabalho e na formação do trabalhador. Logo, podemos afirmar, como Araújo (2019, p. 56), que a Reforma realizada em 2017, representa uma continuidade de uma série de medidas de igual teor "[...] implementadas desde a década de 1990 no Brasil, que visavam subordinar a educação e, em particular, o Ensino Médio, às demandas imediatas dos setores produtivos, conferindo-lhe um caráter mais instrumental".

Como chamamos a atenção no texto, os discursos da empregabilidade e do empreendedorismo, das competências, da crise do Estado e de sua suposta falência serviram e servem de esteio para as ações governamentais, que, rezando na cartilha do neoliberalismo, caminham no sentido de concretizar, regulamentar, confirmar e escancarar a dualidade na educação brasileira.

\section{REFERÊNCIAS}

ARAÚJO, R. M. L. Ensino médio brasileiro: dualidade, diferenciação escolar e reprodução das desigualdades sociais. Uberlândia: Navegando Publicações, 2019. 
DOI: $10.12957 / \mathrm{e}-\mathrm{mosaicos} .2019 .46589$

ARAÚJO, R. M. L.; RODRIGUES, D. S. Referências sobre práticas formativas em educação profissional: o velho travestido de novo frente ao efetivamente novo. Boletim Técnico do SENAC. Rio de Janeiro, v. 36, n.2, p. 51-63, maio/ago. 2010.

BRASIL. Presidência da República. Decreto no 350, de 21 de novembro de 1991. Promulga o Tratado para a Constituição de um Mercado Comum entre a República Argentina, a República Federativa do Brasil, a República do Paraguai e a República Oriental do Uruguai (TRATADO MERCOSUL). Brasília, DF: Presidência da República, 1991. Disponível em: http://www.planalto.gov.br/ccivil_03/decreto/19901994/D0350.htm. Acesso em: 5 Out. 2019.

BRASIL. Presidência da República. Decreto no 2.208, de 17 de abril de 1997. Regulamenta o §2. ${ }^{\circ}$ do artigo 36 e os artigos 39 a 42 da Lei 9.394, de 20 de dezembro de 1996. Brasília, DF: Presidência da República, 1997a. Disponível em: http://www.planalto.gov.br/ccivil_03/decreto/D2208.htm. Acesso em: 1 nov. 2019.

BRASIL. Ministério da Educação. Portaria no 646, de 14 de maio de 1997.

Regulamenta a implantação do disposto nos artigos 39 a 42 da Lei Federal no 9.394/96 e no Decreto n 2.208/97 e dá outras providências. Brasília, DF: Ministério da Educação, 1997b. Disponível em:

http://portal.mec.gov.br/setec/arquivos/pdf/PMEC646_97.pdf. Acesso em: 1 nov. 2019.

BRASIL. Ministério da Educação. Portaria n 1.005, de 10 de setembro de 1997. Implementa o Programa de Reforma da Educação Profissional - PROPEP. Brasília, DF: Ministério da Educação, 1997c. Disponível em:

http://portal.mec.gov.br/setec/arquivos/pdf/PMEC1005_97.pdf. Acesso em: 1 nov. 2019.

BRASIL. Conselho Nacional de Educação. Resolução n 4, de 08 de dezembro de 1999. Institui as Diretrizes Curriculares Nacionais para a Educação Profissional de Nível Técnico. Brasília, DF: Conselho Nacional de Educação, 1999. Disponível em: http://portal.mec.gov.br/setec/arquivos/pdf/RCNE_CEB04_99.pdf. Acesso em: 3 nov. 2019.

BRASIL. Presidência da República. Decreto no 5.154, de 23 de julho de 2004. Regulamenta o $\S 2^{\circ}$ do art. 36 e os arts. 39 a 41 da Lei no 9.394, de 20 de dezembro de 1996, que estabelece as diretrizes e bases da educação nacional, e dá outras providências. Brasília, DF: Presidência da República, 2004. Disponível em: http://www.planalto.gov.br/ccivil_03/_ato2004-2006/2004/decreto/d5154.htm. Acesso em: 1 nov. 2019.

BRASIL. Ministério da Educação. PROEP 2006: Relatório de Progresso. Brasília, DF: 
DOI: $10.12957 / \mathrm{e}-\mathrm{mosaicos} .2019 .46589$

Ministério da Educação, 2006.

BRASIL. Presidência da República. Lei no 13.415/2017, de 16 de fevereiro de 2017. Altera as Leis no 9.394, de 20 de dezembro de 1996, que estabelece as diretrizes e bases da educação nacional, e 11.494, de 20 de junho 2007, que regulamenta 0 Fundo de Manutenção e Desenvolvimento da Educação Básica e de Valorização dos Profissionais da Educação, a Consolidação das Leis do Trabalho - CLT, aprovada pelo Decreto-Lei $n^{\circ} 5.452$, de $1^{\circ}$ de maio de 1943, e o Decreto-Lei $n^{\circ} 236$, de 28 de fevereiro de 1967; revoga a Lei no 11.161, de 5 de agosto de 2005; e institui a Política de Fomento à Implementação de Escolas de Ensino Médio em Tempo Integral. Brasília, DF: Ministério da Educação, 2017a. Disponível em: http://www.planalto.gov.br/ccivil_03/_Ato2015-2018/2017/Lei/L13415.htm. Acesso em: 25 out. 2019.

BRASIL. Ministério da Educação. Referenciais curriculares para a elaboração de itinerários formativos. Brasília, DF: Ministério da Educação, 2017b. Disponível em: http://novoensinomedio.mec.gov.br/resources/downloads/pdf/DCEIF.pdf. Acesso em: 25 out. 2019.

CIAVATTA, M. A formação integrada: a escola e o trabalho como lugares de memória e de identidade. In: FRIGOTTO, G.; CIAVATTA, M.; RAMOS, M. (Org.). Ensino Médio Integrado: concepções e contradições. São Paulo: Cortez, 2012. p. 83-106.

FREIRE, P. Pedagogia do oprimido. Rio de Janeiro: Nova Fronteira, 2012.

FRIGOTTO, G. A produtividade da escola improdutiva. 9. ed. São Paulo: Cortez, 2018.

FRIGOTTO, G. Apresentação. In: ARAÚJO, R. M. L. Ensino médio brasileiro: dualidade, diferenciação escolar e reprodução das desigualdades sociais. Uberlândia: Navegando Publicações, 2019. p. 1-7.

FRIGOTTO, G.; CIAVATTA, M. Educar o trabalhador cidadão produtivo ou o ser humano emancipado? Trabalho, Educação e Saúde. Rio de Janeiro, v. 1, n. 1, 2003. p. $45-60$.

FRIGOTTO, G.; CIAVATTA, M.; RAMOS, M. A gênese do Decreto n. 5.154/2004: um debate no contexto controverso da democracia restrita. In: FRIGOTTO, G.; CIAVATTA, M.; RAMOS, M. (Org.). Ensino Médio Integrado: concepções e contradições. São Paulo: Cortez, 2012. p. 21-56.

FRIGOTTO, G. Anos 1980 e 1990: a relação entre o estrutural e o conjuntural e as políticas de educação tecnológica e profissional. In: FRIGOTTO, G; CIAVATTA, M. 
DOI: $10.12957 / \mathrm{e}-m o s a i c o s .2019 .46589$

(Org.). A formação do cidadão produtivo: a cultura de mercado no ensino médio técnico. Brasília: INEP, 2006. p. 25-54.

GRAMSCI, A. Caderno 12 (1932): apontamentos e notas dispersas para um grupo de ensaios sobre a história dos intelectuais. In: GRAMSCI, A. Cadernos do Cárcere, Volume 2 (Os intelectuais. O princípio educativo. Jornalismo). 2. ed. Rio de Janeiro: Civilização Brasileira, 2001. p. 11-53.

HARVEY, D. O neoliberalismo: história e implicações. São paulo: Loyola, 2008.

KUENZER, A. Z. O ensino médio no contexto das políticas públicas de educação no Brasil. Revista Brasileira de Educação, Rio de Janeiro, n. 4, p. 77-95, jan./abr., São Paulo, 1997. Disponivel em:

http://www.anped.org.br/sites/default/files/rbe/files/rbe_04.pdf Acesso em: 25 out. 2019.

KUENZER, A. Z. Exclusão includente e inclusão excludente: a nova forma de dualidade estrutural que objetiva as novas relações entre educação e trabalho. In: SAVIANI, D; SANFELICE, J. L.; LOMBARDI, J. C. (Org.). Capitalismo, trabalho e educação. 3. ed. Campinas: Autores Associados, 2005. p. 77-96.

KUENZER, A. Z. Primeira Parte. In: KUENZER, A. Z. (Org.). Ensino Médio: construindo uma proposta para os que vivem do trabalho. 6. ed. São Paulo: Cortez, 2009. p. 25-90.

LIMA, A. P. M.; SOUZA, F. L.; SOUZA, F. C. S. Educação profissional técnica de nível médio na forma concomitante: análise da produção do conhecimento. Revista Temas em Educação. João Pessoa, v. 27, n. 2, jul/dez 2018. p. 27-61.

KRAWCZYK, N.; FERRETTI, C. J. Flexibilizar para quê? mais verdades da "reforma". Retratos da Escola. v. 11, n. 20, jan/jun 2017. p. 33-44.

MANFREDI, S. M. Educação profissional no Brasil: atores e cenários ao longo da história. Jundiaí: Paco Editorial, 2016.

MOLL, J. Reformar para retardar: a lógica da mudança no EM. Retratos da Escola. Brasília, v. 11, n. 20, jan/jun 2017. p. 61-74.

MOURA, D. H. Educação básica e educação profissional e tecnológica: dualidade histórica e perspectivas de integração. Holos. Natal, v. 2, n. 23, 2007. p. 4-30.

MOURA, D. H.; LIMA FILHO, D. L. A reforma do ensino médio: regressão de direitos sociais. Retratos da Escola. Brasília, v. 11, n. 20, jan/jun. 2017. p. 109-129. 
DOI: $10.12957 / \mathrm{e}-\mathrm{mosaicos} .2019 .46589$

OLIVEIRA, R. A possibilidade da escola unitária na sociedade capitalista. Cadernos de Educação. Pelotas, n. 32, jan/abr 2009. p. 141-160.

OLIVEIRA, R. A (des)qualificação da Educação Profissional Brasileira. São Paulo: Cortez Editora, 2003.

RAMOS, M. Possibilidades e desafios na organização do currículo integrado. In: FRIGOTTO, G.; CIAVATTA, M.; RAMOS, M. (Org.) Ensino médio integrado: concepções e contradições. 3. ed. São Paulo: Cortez, 2012. p. 107-128.

SAVIANI, D. Sobre a concepção de politecnia. Rio de Janeiro: Fiocruz, 1989.

SAVIANI, D. O choque teórico da politecnia. Trabalho, Educação e Saúde. Rio de Janeiro, v.1, n.1, 2003. p. 131-152.

SAVIANI, D. Trabalho e educação: fundamentos ontológicos e históricos. Revista Brasileira de Educação. Rio de Janeiro, v. 12, n. 32, jan-abr. 2007. p. 152-180.

SHIROMA, O. E.; MORAES, M. C. M.; EVANGELISTA, O. Política Educacional. 4. ed. Rio de Janeiro: Lamparina, 2011.

SILVA, T. T. O projeto educacional da nova direita e a retórica da qualidade total. In: SILVA, T. T.; GENTILI, P. (Org.) A escola S.A.: quem ganha e quem perde no mercado educacional do neoliberalismo. Brasília: CNTE, 1996. p. 167-188.

SOUZA, F. C. S.; SOUZA, F. L.; COSTA JÚNIOR, J. G. B. Ensino médio integrado: a produção do conhecimento nos anos 2007 a 2017. Revista Eletrônica Científica Ensino Interdisciplinar. Mossoró, v. 4, n. 12, 2018.

Recebido em 10 de novembro de 2019

Aceito em 12 de dezembro de 2019

\footnotetext{
(c) (†) \&

A e-Mosaicos Revista Multidisciplinar de Ensino, Pesquisa, Extensão e Cultura do Instituto de Aplicação Fernando Rodrigues da Silveira (CAp-UERJ) está licenciada com uma Licença Creative Commons - Atribuição-NãoComercial 4.0 Internacional.

Os direitos autorais de todos os trabalhos publicados na revista pertencem ao(s) seu(s) autor(es) e coautor(es), com o direito de primeira publicação cedido à e-Mosaicos.

Os artigos publicados são de acesso público, de uso gratuito, com atribuição de autoria obrigatória, para aplicações de finalidade educacional e não-comercial, de acordo com o modelo de licenciamento Creative Commons adotado pela revista.
} 